\title{
A COMPARATIVE STUDY OF ORAL DEXMEDETOMIDINE VERSUS ORAL MIDAZOLAM AS PREANESTHESIA MEDICATION IN PEDIATRIC PATIENTS TO REDUCEANXIETY
}

\author{
Gauchan $S^{1^{*}}$, Thapa $C^{2}$, Prasai $A^{3}$
}

\section{Affiliation}

1. Assistant Professor, Department of Anesthesiology, Nepal Medical College and Teaching Hospital, Jorpati, Kathmandu, Nepal.

2. Lecturer, Department of Anesthesiology, Nepal Medical College and Teaching Hospital, Jorpati, Kathmandu, Nepal

3. Senior Consultant, Department of Anesthesiology, Nepal Medical and College Teaching Hospital, Jorpati, Kathmandu, Nepal

\section{ARTICLE INFO}

\begin{tabular}{lll}
\hline Received & : & 15 June, 2019 \\
Accepted & $:$ & 07 August, 2019 \\
Published & $:$ & 31 August, 2019
\end{tabular}

(c) Authors retain copyright and grant the journal right of first publication with the work simultaneously licensed under Creative Commons Attribution License CC - BY 4.0 that allows others to share the work with an acknowledgment of the work's authorship and initial publication in this journal.

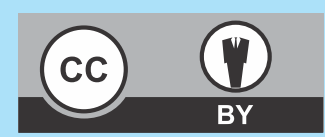

ORA 121

DOI: http://dx.doi.org/10.3126/bjhs.v4i2.25453

$$
\begin{gathered}
* \text { Corresponding Author } \\
\text { Dr. Sabin Gauchan } \\
\text { Nepal Medical College and Teaching Hospital } \\
\text { Jorpati, Kathmandu, Nepal. } \\
\text { Email ID: sabingauchan@gmail.com. } \\
\text { ORCID ID: https://orcid.org/0000-0003-1672-4532 }
\end{gathered}
$$

\section{Citation}

Gauchan S, Thapa C, Prasai A. A Comparative Study of Oral Dexmedetomidine Versus Oral Midazolam Aspreanesthesia Medication in Pediatric Patients to Reduceanxiety. BJHS 2019;4(2)9: 724 - 728.

\section{ABSTRACT}

\section{Introduction}

Preoperative period is a stressful period. In children the preoperative anxiety is expressed as difficult separation from parents and difficult mask induction. The level of preoperative anxiety also affects postoperative outcomes. To overcome anxiety premedication is often used by pediatric anesthesiologist.

\section{Objective}

The objective of this study was to compare the effect of oral midazolam $0.5 \mathrm{mg} / \mathrm{kg}$ and oral dexmedetomidine $4 \mu \mathrm{g} / \mathrm{kg}$ on parental separation, mask induction and postoperative emergence agitation in children undergoing elective surgery under general anesthesia.

\section{Methodology}

120 children aged 2-8years undergoing elective surgery under general anesthesia were divided into two groups: Group M and Group D. Patients in group M received oral midazolam $0.5 \mathrm{mg} / \mathrm{kg}$ and patients in group $D$ received oral dexmedetomidine $4 \mu \mathrm{g} / \mathrm{kg}$. After $45 \mathrm{~min}$ of premedication sedation score was assessed in both the groups. Ease of parental separation and mask acceptance was compared in both the groups. In the postoperative period occurrence of emergence agitation was compared in both the groups.

\section{Results}

There was no statistically significant difference in preoperative sedation score in both the groups. Parent separation anxiety score and mask acceptance score were statistically similar in both the groups. But emergence agitation was significantly lesser in patients who received dexmedetomidine premedication.

\section{Conclusions}

Premedication with oral midazolam as well as oral dexmedetomidine effectively reduces parental separation anxiety and produces satisfactory mask induction in pediatric age group. However, dexmedetomidine is more effective in reducing emergence delirium in comparison to midazolam.

\section{KEY WORDS}

Anxiety, dexmedetomidine, midazolam, pediatric 


\section{INTRODUCTION}

Incidence of preoperative anxiety in pediatric population is about $60-70 \%{ }^{1}$ Children become uncooperative, anxious, fearful especially at the time of separation from parents, venepuncture, or mask application at the time of induction. Untreated anxiety is associated with an increased incidence of difficult induction, postoperative agitation, and increased analgesic requirements. ${ }^{2}$ Delayed psychological and behavioral changes such as night-time crying, enuresis, anorexia and temper tantrums can also result from excessive perioperative anxiety. ${ }^{2}$

Hence preoperative anxiolysis is an important part of pediatric anesthesia and is often accomplished by prior administration of a sedative drug. It minimizes distress in children entering the operating room and facilitates smooth induction and recovery. Midazolam is one of the commonly used drugs for this purpose. ${ }^{3,4}$ It has been used orally in the dose of $0.5 \mathrm{mg} / \mathrm{kg}$ and has been found to be effective in reducing separation and induction anxiety, with minimal effect on recovery time. ${ }^{5}$ But it is not the ideal premedicant in children as its use has been associated with undesirable effects including restlessness, paradoxical reaction, respiratory depression and negative postoperative behavioral changes. ${ }^{6.8}$ Dexmedetomidine is a newer $\alpha 2$ agonist with a more selective action on the a2adrenoceptor that provides sedation, anxiolysis and analgesia with minimal respiratory depression. Because of the favorable safety profile its use in anesthesia is increasing. In our institute dexmedetomidine has been used as an adjuvant to local anesthetic drugs in brachial plexus block, in subarachnoid block, it has also been used intravenously in attenuation of hemodynamic reflexes to intubation. We have been using oral midazolam for premedication in pediatric patients but dexmedetomidine has not been used till now. Looking at the positive results of dexmedetomidine premedication in pediatric population this randomized double blind study was designed to compare this newer drug with the conventionally used premedicant midazolam in children.

\section{METHODOLOGY}

This was a randomized double blind study done in Nepal Medical College and Teaching Hospital from Jan 2016 to Sep 2017. After obtaining permission from institutional ethical committee, parents of the children were explained about the drug and only those who gave willful written consent were included in the study. One hundred and twenty children of either sex, age 2-8years, belonging to ASA physical status 1 , posted for elective surgeries $<2$ hours of expected duration under general anesthesia were enrolled in this study. Preanesthetic evaluation was done a day before surgery. Children with known allergies to the drugs used in the study, presence of central nervous system disorders including developmental delay or mental retardation and presence of anticipated difficult airway were excluded from the study. Patients were fasted for 6 hrs for solid food and 2 hours for clear liquid before surgery. In the preoperative room, the patients were allocated into two groups: Group D and Group M. Patients in Group D were premedicated with oral Dexmedetomidine $4 \mu \mathrm{g} / \mathrm{kg}$ and patients in Group M were given oral Midazolam $0.5 \mathrm{mg} / \mathrm{kg}$, both the drugs mixed with sugar syrup to a total volume of $5 \mathrm{ml}$. The study drug was prepared by the principal investigator of the research who also did the group allocation by sealed envelope technique. The patient/parent and anesthesiologist managing the patients were blinded to the group allocation. Apart from principal investigator two other anesthesiologists were involved in the study, one observer anesthesiologist and the other attending anesthesiologist. Baseline heart rate, respiratory rate, mean arterial pressure, peripheral oxygen saturation were monitored before premedication and continued after premedication. Fourty fiveminutes after premedication, level of sedation was assessed using Ramsay Sedation Scale: $1=$ patient is anxious and agitated or restless or both; $2=$ patient is cooperative, oriented, and tranquil; $3=$ patient responds to commands only; $4=$ patient exhibits a brisk response to a light glabellar tap; $5=$ patient exhibits a sluggish response to a light glabellar tap; and $6=$ patient exhibits no response. A Ramsay sedation score of " 1 " was considered unsatisfactory and $>2$ as satisfactory level of sedation. Children who spit the medication out or vomited were excluded from the study.

Children were separated from the parent $45-60 \mathrm{~min}$ after premedication, and the behavior of the child on separation from the parents was assessed and graded using parental separation anxiety scale (PSAS) Grade 1: easy separation; Grade 2: Whimpers, but is easily reassured, not clinging; Grade3: Cries and cannot be easily reassured, but not clinging; Grade 4: Crying and clinging to parents. A PSAS score of 1 and 2 was considered as acceptable separation from parents and score of 3 and 4 were taken as unacceptable. ${ }^{9}$

The child was taken inside the operating room. An electrocardiogram, pulse oximeter and non-invasive blood pressure monitor were attached. Induction was done with $8 \%$ Sevoflurane in oxygen. Ease of induction was assessed by 4-point Mask acceptance scale. 1= excellent (unafraid, cooperative, and accepts the mask easily); 2 =good (slight fear of mask, easily reassured); 3 = fair (moderate fear of mask, not calmed with reassurance); and 4=poor (terrified, crying, or combative). Scores of 1 and 2 were considered as satisfactory mask acceptance and scores of 3 and 4 unsatisfactory mask acceptance ${ }^{10,11}$ After achieving adequate depth of anesthesia, an intravenous line was secured with appropriate gauge cannula and inj. Fentanyl $2 \mu \mathrm{g} / \mathrm{kg}$ was given. Muscle relaxation was achieved with vecuronium $0.1 \mathrm{mg} / \mathrm{kg}$. After ventilation with sevoflurane $5 \%$ in oxygen for $3 \mathrm{~min}$, the airway was secured with an appropriate size endotracheal tube. Anesthesia was maintained with titrated concentration of sevoflurane in oxygen and vecuronium as required and positive pressure ventilation. At the end of surgery paracetamol suppository $15 \mathrm{mg} / \mathrm{kg}$ was placed per rectal. Duration of surgery was noted. Residual effect of neuromuscular block was reversed with neostigmine and glycopyrrolate. Once the child was breathing 
spontaneously, extubation was done and the child was placed in recovery position and transferred to post anesthesia care unit. Time to recovery (defined as time interval between discontinuation of sevoflurane and extubation) was also noted.

In the post anesthesia care unit, mean arterial pressure (MAP), heart rate and $\mathrm{SpO} 2$ was monitored. Occurrence and severity of emergence agitation was measured using Pediatric anesthesia emergence delirium scale (PAEDS) at 0 , 30 and 60 min postoperatively.

The PAEDS is used to assess patients on five psychometric items:1. The child makes eye contact with the caregiver. 2. The child's actions are purposeful. 3. The child is aware of his or her sorroundings. 4. The child is restless. 5. The child is inconsolable. Items 1,2 and 3 were reversed scored as follows: 4=not at all; $3=$ =just a little; $2=$ quite a bit; $1=$ very much; $0=$ extremely. Items 4 and 5 are scored as follows: $0=$ not at all; 1 =just a little; 2 = quite a bit; 3 =very much; and $4=$ extremely. The scores of each item were summed to obtain a total PAEDS score. A score of $\geq 10$ was considered as the presence of emergence delirium. ${ }^{11,12}$

Scoring for all the scales used in the study and monitoring of the patient was done by the observer anesthesiogist.

The sample size was calculated by using the formula $\mathrm{n}=\mathrm{z}^{2} \mathrm{pq} / \mathrm{d}^{2}$

where $z^{2}=1.96^{2}$

$p=92.3$ (based on the study conducted by Sultan et al. ${ }^{13}$ in which they had successful parental separation in $92.3 \%$ of patients)

$$
\begin{aligned}
& q=1-p \\
& d=7 \text { (allowable error) }
\end{aligned}
$$

The minimum sample size required was 56 in each group.

The data was compiled and subjected to statistical analysis using Statistical Package for Social Sciences (SPSS), version 16.

\section{RESULTS}

A total of 120 children were enrolled in the study. All the children could be convinced to take oral premedication.

Demographic data (age, weight, gender) were comparable in both the groups (Table1). Duration of surgery and time to recovery from anesthesia were similar in both the groups (Table 2). Sedation score after 45 min of premedication was comparable in both the groups (Table 3). 59 patients in group $M$ and 57 patients in group $D$ had satisfactory sedation level at $30 \mathrm{~min}$ of premedication. None of the patient was unresponsive in both the groups. Parental separation anxiety score and mask acceptance score was comparable between two groups (Table 4 and Table 5).

Emergence delirium at 0 and $30 \mathrm{~min}$ postoperatively was significantly less in group $D$ than in group $M$ (Table 6 ). However emergence delirium at $60 \mathrm{~min}$ was statistically similar in both the groups. Only 1 patient had hypotension and bradycardiain group D (Table 7). Hypoxia was not seen in any of the patients in two group.

\begin{tabular}{lccc}
\multicolumn{2}{l}{ Table 1: Demographic data } \\
Parameter & Group M & Group D & P value \\
\hline $\begin{array}{l}\text { Age(years) } \\
\text { (Mean } \pm \text { SD) }\end{array}$ & $4.82 \pm 1.58$ & $4.81 \pm 1.63$ & 0.96 \\
$\begin{array}{l}\text { Body weight(kg) } \\
\text { (Mean } \pm \text { SD) }\end{array}$ & $21 \pm 6$ & $22.6 \pm 8.7$ & 0.23 \\
$\begin{array}{l}\text { Gender } \\
\text { (male/female) }\end{array}$ & $45: 15$ & $44: 16$ & 0.83 \\
\hline
\end{tabular}

\begin{tabular}{lccr}
\hline \multicolumn{4}{|c}{ Table 2: Duration of surgery and time to recovery } \\
\multicolumn{1}{|c}{ Parameter } & Group M & Group D & P value \\
\hline $\begin{array}{l}\text { Duration of surgery } \\
\text { (min) }\end{array}$ & $59.36 \pm 10.98$ & $60.25 \pm 11.4$ & 0.66 \\
$\begin{array}{l}\text { Time to recovery }(\mathrm{min}) \\
\text { Time }\end{array}$ & $9.75 \pm 1.85$ & $9.7 \pm 2.26$ & 0.96
\end{tabular}

Table 3: : Sedation Score after $45 \mathrm{~min}$ of premedication

$\begin{array}{lccc}\begin{array}{c}\text { Sedation score } \\ \text { 45min }\end{array} & \text { Group M } & \text { Group D } & \text { P value } \\ \text { Satisfactory } & 59(98.3 \%) & 57(95 \%) & 0.61 \\ \text { Unsatisfactory } & 1 & 3 & \\ \text { Unresponsive } & 0 & 0 & \end{array}$

\begin{tabular}{|c|c|c|c|}
\hline Mask acceptance & Group M & Group D & pvalue \\
\hline Satisfactory & 59(98.3\%) & $57(95 \%)$ & 0.61 \\
\hline unsatisfactory & 1 & 3 & \\
\hline
\end{tabular}

Table 4: : Parent separation anxiety score (PSAS)
$\begin{array}{lccc}\text { PSAS } & \text { Group M } & \text { Group D } & \text { pvalue } \\ \text { Acceptable } & 57(95 \%) & 58(96.6 \%) & 1 \\ \text { Not acceptable } & 3 & 2 & \end{array}$

Table 6: Paediatric anesthesia emergence delirium Scale (PAEDS)

PAEDS Group M Group D pvalue

$\begin{array}{lccc}\text { PAEDS 0 } & & & \\ \text { Present } & 25 & 1 & 0.00 \\ \text { absent } & 35 & 59 & \end{array}$

$\begin{array}{llll}\text { PAEDS } 30 & & & \\ \text { Present } & 13 & 0 & 0.00\end{array}$

absent $\quad 47 \quad 60$

\section{PAEDS 60}

$\begin{array}{llll}\text { Present } & 3 & 0 & 0.24\end{array}$

$\begin{array}{lll}\text { Absent } & 57 & 60\end{array}$

\begin{tabular}{lccc}
\hline $\begin{array}{l}\text { Table 7: Adverse Effects } \\
\text { Adverse effects }\end{array}$ & Group M & Group D & Pvalue \\
\hline Hypotension & 0 & 1 & 1 \\
Bradycardia & 0 & 1 & 1 \\
hypoxia & 0 & 0 &
\end{tabular}




\section{DISCUSSION}

This study demonstrated that premedication with $4 \mu \mathrm{g} / \mathrm{kg}$ oral dexmedetomidine and $0.5 \mathrm{mg} / \mathrm{kg}$ of oral midazolam provided satisfactory sedation, satisfactory parent separation and satisfactory mask acceptance in children 28 years of age who underwent elective surgery under general anesthesia. Dexmedetomidine was found to effectively reduce the occurrence of emergence delirium compared to midazolam.

Oral midazolam is a commonly used drug for premedication in pediatric anesthesia. It facilitates gamma amino butyric acid receptor-mediated chloride conductance, which has an inhibitory effect on neurons in the cerebral cortex. Dexmedetomidine acts on central $\alpha 2$-receptors located at the locus ceruleus causing inhibition of release of noradrenaline and create electroencephalogram activity similar to normal sleep. This results in anxiolytic effects, sedation and analgesia without respiratory depression.

Oral route is widely used for premedication, however it results in lower bioavailability. The bioavailability of oral midazolam varies from $15 \%$ to $27 \%$ in children ${ }^{14}$ whereas the bioavailability of oral dexmedetomidine is reported to be $16 \%{ }^{14}$ Intranasal route is another commonly used route for premedication in pediatric population as it has a rich mucosal blood supply and bypasses the first-pass metabolism resulting in a better bioavailability. But intranasal administration of midazolam causes nasal irritation. ${ }^{15}$ Therefore we chose to administer the drugs orally. Oral midazolam has a bitter taste, to make the drug palatable we mixed the drug in sugar solution. None of the children spit out the drug. Dexmedetomidine on the other hand is colorless, odorless and tasteless.

The dose of midazolam used widely in clinical practice is oral $0.5 \mathrm{mg} / \mathrm{kg}$; intranasal $0.2 \mathrm{mg} / \mathrm{kg}$, while that of dexmedetomidine is mostly empirical oral $2.5-4 \mu \mathrm{g} / \mathrm{kg}$; intranasal $1-2 \mu \mathrm{g} / \mathrm{kg} .{ }^{16}$ The mean bioavailability of dexmedetomidine is $16 \%$ by oral route and $81.8 \%$ by transmucosal route. Considering four times more bioavailability by transmucosal route as compared to oral, an oral dose of $4 \mu \mathrm{g} / \mathrm{kg}$ was chosen for our study.

In the studies done by Sultan Keles et $\mathrm{al}^{13}$ and Binu Sajid et $\mathrm{al}^{17}$, the sedation scores were found to be satisfactory after 30 min of premedication with both midazolam as well as dexmedetomidine. Jannu et al ${ }^{18}$ compared the onset and peak sedation of oral midazolam and dexmedetomidine in children. They found an early onset of sedation and a faster peak sedative effect in midazolam group as compared to dexmedetomidine. Yuen et al ${ }^{19}$ demonstrated that intranasal 1 and $1.5 \mu \mathrm{g} / \mathrm{kg}$ dexmedetomidine produces sedation in 45-60min and peaks in 90-105min. Based on these studies we premedicated the children at least $45 \mathrm{~min}$ prior to transfer to operation theatre. In our study, the sedation score at $45 \mathrm{~min}$ after premedication was similar in both the groups. In midazolam group, $98.3 \%$ of children and in dexmedetomidine group, $95 \%$ of children had satisfactory sedation. None of the patients became unresponsive in both the groups.
Parental separation and mask induction are the moments of maximum anxiety in children. One of the goals of premedication in pediatric population is to ease parental separation and mask induction. In our study $95 \%$ of children in the midazolam group and $96.6 \%$ of children in the dexmedetomidine group had acceptable parental separation and $98.3 \%$ of children in midazolam group and $95 \%$ of children in dexmedetomidine group had satisfactory mask acceptance. Both the drugs provided acceptable parent separation and smooth mask induction. Mountain et $\mathrm{al}^{20}$ compared $4 \mu \mathrm{g} / \mathrm{kg}$ of oral dexmedetomidine and $0.5 \mathrm{mg} / \mathrm{kg}$ of midazolam, dosage similar to our study, and found acceptable parent separation and satisfactory mask acceptance in both the groups. Similarly Binu Sajidet al $^{17}$ found no significant difference in the parental separation anxiety in children when they compared $4 \mu \mathrm{g} / \mathrm{kg}$ of oral dexmedetomidine and $0.5 \mathrm{mg} / \mathrm{kg}$ of midazolam as premedication.

Emergence agitation (EA) is another commonly encountered problem in pediatric anesthesia. It is defined as a disturbance in a child's awareness of and attention to his/ her environment with disorientation and perceptual alterations including hypersensitivity to stimuli and hyperactive motor behavior in the immediate postanesthesia period. Prevalence of emergence agitation in children has been reported to be $20 \%$ to $30 \%{ }^{21,22}$ During EA, children risk injuring themselves by dislodging intravenous tubing or drains, losing a skin graft, bleeding from the operative site, increasing their pain, and injuring their caregivers. The child's behavior can be disruptive to the PACU and often requires increased nursing supervision, which strains nursing resources. Premedication has been of advantage in controlling EA in children. In our study dexmedetomidine was more effective in suppressing EA compared to midazolam till $30 \mathrm{~min}$ in the postoperative period. PAED score at 60 min was similar in both the groups. Batawi et al ${ }^{23}$ studied the effect of preoperative oral midazolam sedation on separation anxiety and emergence delirium among children undergoing dental treatment. They found that preoperative midazolam has no reducing effect on postoperative emergence delirium in children. Prabhu and Mehandale ${ }^{24}$ compared the effect of $4 \mu \mathrm{g} / \mathrm{kg}$ oral dexmedetomidinevs $0.5 \mathrm{mg} / \mathrm{kg}$ of oral midazolam as premedication and concluded that oral dexmedetomidine is superior to oral midazolam for reducing the incidence (from $40 \%$ to $4.4 \%$ ) of emergence delirium. Sultan Keles et al ${ }^{13}$ also had similar finding in terms of emergence delirium, they showed a significantly lower emergence delirium score in dexmedetomidine group as compared to midazolam group.

In our study, there were no significant episodes of hypotension, bradycardia and hypoxia in both the groups.

\section{CONCLUSION}

Premedication with oral midazolam as well as oral dexmedetomidine effectively reduces parental separation anxiety and produces satisfactory mask induction in pediatric age group. However, dexmedetomidine is more effective in reducing emergence delirium in comparison to midazolam. 


\section{RECOMMENDATION}

We recommend premedication with oral dexmedetomidine $4 \mu \mathrm{g} / \mathrm{kg}$ at least $45 \mathrm{~min}$ prior to induction for easy parental separation, satisfactory mask inductionin and reduced postoperative emergence agitation in pediatric patients.

\section{LIMITATION OF THE STUDY}

There were few limitations in this clinical study. As oral formulation of the drugs are not available, IV formulations were given as oral preparation. We did not evaluate the onset time and peak effect of the two drugs in the preoperative period. The surgical procedure in our study was heterogenous and the intensity of pain varies with the surgical procedure, this might have influenced emergence agitation.

\section{REFERENCES}

1. Watson AT, Visram A. Children's preoperative anxiety and post operative behaviour. PediatrAnesth 2003; 13:188-204. PMID: 12641680

2. Rosenbaum A, Kain ZN, Larsson P,Lonnqvist PA, Wolf AR. The place of premedication in pediatric practice. PediatrAnesth 2009;19:81728.doi: 10.1111/j.1460-9592.2009.03114.x.

3. Kain ZN, Caldwell- Andrews AA, Krivutza DM, Weinberg ME, Wang S$M$, Gaal D. Trends in the practice of parental presence during induction of anesthesia and the use of preoperative sedative premedication in the United States,1995-2002: results of a follow up national survey. AnesthAnalg 2004;98:1252-9.DOI:10.1213/01. ane.0000111183.38618.d8

4. Kain ZN, Mayes LC, Wang SM, Caramico LA, Hofstadter MB, Rimar S Premedication in the United States: a status report. AnesthAnalg 1997;84:427-32.DOI:10.1097/00000539-199702000-00035

5. Cox RG, Nemish U, Ewen A, Crowe M-J. Evidence-based clinical update: does premedication with oral midazolam lead to improved behavioural outcomes in children? Can J Anaesth 2006;53:1213-19. DOI: 10.1007/BF03021583

6. Lonnqvist PA, Habre W. Midazolam as premedication: is the emperor naked or just half-dressed? PaediatrAnaesth 2005;15:2635.DOI:10.1111/j.1460-9592.2005.01600.x

7. Kanegaye JT, Favela JL, Acosta M, Bank DE. High-dose rectal midazolam for pediatric procedures: A randomized trial of sedative efficacy and agitation. PediatrEmerg Care 2003;19:329-36.PMID:14578832

8. McGraw T, Kendrick A. Oral midazolam premedication and postoperative behaviour in children. PaediatrAnaesth 1998;8:11721. https://doi.org/10.1046/j.1460-9592.1998.00724.x

9. Dashiff CJ, Weaver M. Development and testing of a scale to measure separation anxiety of parents of adolescents. J Nurs Meas. 2008;16 (1):61-80.PMID:18578110

10. Weldon BC, Watcha MF, White PF. Oral midazolam in children: effect of time and adjunctive therapy. AnesthAnalg. 1992;75(1):51-55. DOI: 10.1213/00000539-199207000-00010

11. Shukry M, Clyde MC, Kalarickal PL, Ramadhyani U. Does dexmedetomidine prevent emergence delirium in children after sevoflurane-based general anesthesia? PediatrAnesth. 2005;15(12): 1098-1104.DOI:10.1111/j.1460-9592.2005.01660.x

12. Sikich N, Lerman J. Development and psychometric evaluation of the pediatric anesthesia emergence delirium scale. Anesthesiology. 2004;100(5):1138-1145.DOI:10.1097/00000542-200405000-00015

13. Sultan Keles, OzlemKocaturk. Comparison of oral dexmedetomidine and midazolam for premedication and emergence delirium in children after dental procedures under general anesthesia: a retrospective study. Drug Des DevelTher 2018;12:647-653.doi: 10.2147/ DDDT. S163828

\section{ACKNOWLEDGMENT}

I would like to thank all the faculty and residents from department of anesthesiology of Nepal Medical College and Teaching Hospital and special thanks goes to Dr. Nischal Dhakal and Dr. Kumud Pyakurel.

\section{CONFLICT OF INTEREST}

Authors declare no conflict of interest.

\section{FINANCIALDISCLOSURE}

None.

14. Kumari S, Agrawal N, Usha G, Talwar V, Gupta P. Comparison of oral clonidine, oral dexmedetomidine, and oral midazolam for premedication in pediatric patients undergoing elective surgery. Anesth Essays Res. 2017;11(1): 185-191.DOI:10.4103/0259-1162.194586

15. Kogan A, Katz J, Efrat R, Eidelman LA. Premedication with midazolam in young children: a comparison of four routes of administration. PaediatrAnaesth. 2002;12(8):685-9.DOI: 10.1046/j.14609592.2002.00918.x

16. Peng K, Wu SR, Ji FH, Li J. Premedication with dexmedetomidine in pediatric patients. A systematic review and meta-analysis. Clinics 2014;69:777-86.DOI:10.6061/clinics/2014(11)12

17. Sajid B, Mohamed T, Jumaila M. A comparison of oral dexmedetomidine and oral midazolam as premedicants in children. J Anesthesiol ClinPharmacol 2019;35:36-40. DOI: 10.4103/joacp.JOACP_20_18

18. Jannu V, Mane RS, Dhorigol MG, Sanikop CS. A comparison of oral midazolam and oral dexmedetomidine as premedication in pediatric anesthesia. Saudi J Anaesth 2016;10:390-4.DOI: 10.4103/1658$354 X .177333$

19. Yuen VM, Hui TW, Yuen MK, Irwin MG. A double blind crossover assessment of the sedative and analgesic effects of intranasal desmedetomidine. AnesthAnalg 2007;105:374-80.DOI:10.1213/01. ane.0000269488.06546.7c

20. Mountain BW, Smithson L, Cramolini M, Wyatt TH, Newman M. Dexmedetomidine as a pediatric anaesthetic to reduce anxiety and to deter emergence delirium. AANA J 2011;79:219-24. PMID:21751690

21. Voepel-Lewis T, Malviya S, Tait AR. A prospective cohort study of emergence agitation in the pediatric postanesthesia care unit. AnesthAnalg. 2003;96(6):1625-1630.DOI:10.1213/01.ane. 0000062522.21048 .61

22. Cole JW, Murray DJ, McAllister JD, Hirshberg GE. Emergence behaviour in children: defining the incidence of excitement and agitation following anaesthesia. PaediatrAnaesth. 2002;12(5):442-447.DOI: 10.1046/j.1460-9592.2002.00868.x

23. HishamYehia El Batawi. Effect of preoperative oral midazolam sedation on separation anxiety and emergence delirium among children undergoing dental treatment under general anesthesia. J IntSocPrev Community Dent. 2015;5(2):88-94.doi: 10.4103/22310762.155728

24. Prabhu MK, Mehandale SG. Comparison of oral dexmedetomidine versus oral midazolam as premedication to prevent emergence agitation after sevoflurane anaesthesia in paediatric patients. Indian J Anaesth 2017;61:131-6.DOI: 10.4103/0019-5049.199852. 